\title{
Reframing Health Care: Philosophy for Medicine and Human Flourishing
}

\author{
By Phil Hutchinson and Rupert Read
}

Introductory comments

An important insight of Fulford's work - which actually precedes his development of 'values-based practice" - is that there is no such thing as "value-free" diagnosis. To characterise a person as having a particular illness is to make a value-laden claim, whether or not people reflect on what the values are that underlie the diagnosis (Fulford 1989). We agree with him on this point, but want to ground a view about the role of value-judgments in diagnosis in a broader conceptual framework-one which argues that there is no such thing as an approach to health care (including the science of medicine) that is "philosophy-free". In what follows we explain and justify this claim before bringing out its significance to Fulford's project and his own underlying assumptions about the relationship between value, philosophy, science and practice.

\section{Medical Science (Philosophy Redundant)}

What business does philosophy have in health care? The application of statistical methods will tell us scientifically which medical interventions and diagnostic procedures are most effective. Statistical analysis, in the form of RCTs and their meta-analysis in Cochrane Collaboration-style systematic reviews, has become the benchmark of good scientific practice. Some still hold that a good scientist will insist on finding support for inductive statistical analysis in explanatory work on biochemical causal mechanisms, but wherever one stands, whether one is a positivist who believes that we really only need concern ourselves with 'Cochrane-style' inductive statistical analysis or whether one thinks it essential to understand the causal mechanisms at work, ${ }^{1}$ this is what health care is: Evidence-Based care, as it is referred to on the Cochrane Collaboration website. This is why what we here refer to as "health care" is widely referred to as, and used interchangeably with, "medical science", and one (valid) reason for this is to differentiate it from quackery, or pseudoscience, such as homeopathy. But does the insistence on seeing health care simply as science, and science of a particular sort, have unfortunate side effects? Is there anything else that can be said, which might qualify as being distinctively medical while falling outside the purview of science?

We ask this because while it has emerged as an assumption of some prominence that philosophy is a sort of proto-science, this is, we submit, a false assumption. Unfortunately, the assumption's falsity does not seem to impact on its prominence. The assumption might be illustrated by the following narrative presentation: psychology is a relatively new science and as such it is discipline occupied by and under siege from many folk assumptions and confusions. Philosophers might hold the fort of psychological reason against attacks from the folk beyond the battlements (and quell the internal insurrections), but all we can really expect from the philosophers is that they can hold the fort, not that they might win the battle and establish law and order. For, the idea is, philosophers are simply not equipped to do that. One day, the philosophers know, the scientific cavalry will arrive. They will thank the philosophers for keepng the flag of reason flying, but tell them they are no longer needed.

\footnotetext{
${ }^{1}$ The bio-statistical community is not as one on this. Some seem to be interested only in inductive statistical analysis, others claim that a scientist must be concerned to explain in terms of the underlying causal mechanisms as a part of the overall explanation. See Bausell (2007) for an example of a bio-statistician who holds the latter view. David Colquhoun seems to be an example of someone who holds the former view.
} 
The real scientists are here. The neuroscientists are here to win the battle once and for all and establish the neuroscientific laws which will govern the region of psychology from here-on-in. If you are a philosopher who insists on sticking around and questioning the laws, then you must be some kind of anarchist (or libertarian cf. David Colquhoun's ad hominem remarks about Michael Loughlin ${ }^{2}$ ). We can exchange "psychology" for "medicine" in this story and the same would apply: on this view, philosophers are redundant following the work of Archie Cochrane and later the emergence of the Evidence-Based Medicine movement in the 1990s. Philosophical hand-wringing about the nature of causality, about whether or not "evidence" is a concept the content of which is specific to particular domains of inquiry, and philosophical arguments about the problems of Positivism and "Problem of Induction" are at best seen as what Taleb (2007) refers to (talking about philosophy in another context) as weekend problems: ${ }^{3}$ problems that we don't need to bother ourselves with Monday to Friday, when the real important work is being undertaken.

What's wrong with this picture? While such a picture might be operative in the subconscious of many scientists ${ }^{4}$, it will appear to most philosophers to rest on a set of crudely inaccurate assumptions about the discipline of philosophy; for while science by-and-large is about explaining real things and how they interact, philosophy is about explaining or understanding the nature of reality at the most general level. How one meets that question-the nature-of-reality questiondetermines what sort of philosopher one is (realist, idealist; cognitivist, non-cognitivist; rationalist, empiricist; and so on). So, while the philosopher's domain is not coextensive with that of the scientists, it is the domain which frames the inquiries of the scientist. (The world has little concern for academic disciplinary boundaries). Philosophers don't seek to answer the questions of science in lieu of the application of scientific methods to those questions, but rather seek to identify distinctively philosophical questions, questions that cannot be readily reduced to scientific questions, (or reduced to mathematical questions, and so on). Philosophers then seek to understand the nature of these questions: e.g. are they answerable, and if so through the adoption of which methods? Linguistic? Experimental? Or do the questions need reformulating or even dissolving?

Where a medical scientist will want to inquire as to what evidential basis there is for the administration of intervention $X$ to treat illness $Y$, the philosopher will want to look at that which frames the question: what makes $Y$ an illness in need of treatment ${ }^{5}$ ? What makes $X$ qualify as something it makes sense to think of as a cure, given the non-curative negative or debilitating effects it has on a person (or society) in addition to its ability to combat the illness? What counts as evidence in specific domains of inquiry?

\section{Medical Science 'Reframed' (Some Philosophical-Ethical Aspects of Health Care)}

So far we have talked of philosophers and scientists, as if one can be uniquely one and not the other. However, philosophy is unavoidable, even for scientists: the thought that philosophy can simply be

\footnotetext{
${ }^{2}$ See Colquhoun's remarks about Loughlin, here: http://bit.ly/1ciC4uV

${ }^{3}$ Taleb's work might in other ways provide support for the line of thought we shall pursue in the present paper. In future work, we hope to lay out how genuinely precautionary / 'via negativa' thinking may undermine EBM and VBP. See also n.14 \& section 6, below.

${ }^{4}$ See, for example, the recent remarks of Peter Atkins (2011) and Stephen Hawking (2010). See Hutchinson's discussion of these claims in his "What Have the Philosophers Ever Done For Us?" (see fn 2, above, for link/web address)

${ }^{5}$ See, for example, Havi Carel's work.
} 
forgone, based in the assumption that it is a proto-science and therefore redundant once we earn the right to drop the "proto-" prefix, is a profound error which contributes to philosophical naiveté and serves to justify philosophical ignorance. The naiveté is to be found in the extent to which one will be missing the distinctively philosophical aspects of one's inquiry; the ignorance will seem justified because in missing those distinctively philosophical aspects one will feel justified in ignoring philosophical suggestions, objections and corrections that might well be pertinent (or dismissing them as being only of interest at the weekend, when the real work has been completed). Rejection of philosophy does not amount to what one might be tempted to assume: it is not to forgo actually doing philosophy, in favour of rigorous science or philosophy-free science; rather it is to commit oneself to doing spontaneous philosophy. Philosophy is unavoidable. Philosophical assumptions frame our investigations, whatever discipline provides the home for those investigations. It is important how our questions are framed. For example, framing certain psychological questions in the same way as one might frame non-psychological medical questions might well result in the misidentification/confusion of symptoms and causes. Philosophy is not an add-on, but always present. It is not what one does when one is still waiting for the frontiers of science to extend to and encompass one's domain. Philosophical assumptions frame what one does and, therefore, leaving those assumptions unexamined is to simply accept the frames bestowed by happenstance. So, to return to the question with which we began: what business does philosophy have in health care?

Beyond the identification of effective medical interventions and effective diagnostic practices (the science part, allegedly) there exist of course concerns about the appropriate ways people might interact, the appropriate ways in which people might be used in drug trials, questions of physicianassisted dying, questions of stem cell research, cloning and so on. One can see these as ethical questions which are separate from the science of health care. So, while one might argue that medical epistemology is the domain of the sciences, beyond that there are questions of an ethical character. Some of those ethical questions are discussed by bio-ethicists, such as questions of stem cell research and cloning; while some are left to professional ethics committees, such as the appropriate ways in which people might be used in trials, for example. But if we leave things at this, we simply accept the frames as they are currently set by medical science. Let's try a little reframing.

Consider the norms governing the physician/surgeon-patient relationship, or more specifically consider the norms in play when a surgeon advises a patient on a particular surgical intervention for preventative reasons: a mastectomy, for example; or a prostatectomy. One might be tempted to suggest that the surgeon's judgement here should be guided purely by the balance of probabilities, and in suggesting so one might believe this to be a domain that falls well within the purview of the statistical sciences. The judgment should be evidence-based. But in talking of balancing probabilities, what, beyond (or behind) the numbers, is being balanced? Let us assume that there is a statistically high risk of cancer on the one hand, what are we asking our surgeon to balance this against? Does the surgeon need to have empathetic understanding of a life without breasts or a life lived with a high likelihood of erectile dysfunction? Or does the surgeon need only to have consulted the QoLs ${ }^{6}$ for those who live a life under the threat of cancer, undergoing regular tests, and then later have to undergo a long debilitating course of chemotherapy in comparison to those who live without the threat, without the tests, and without the chemo, but also have to come to terms with living without their breasts and with massive scars (mastectomy) or with a high likelihood of incontinence and/or

\footnotetext{
${ }^{6}$ See Loughlin (2002) Ethics, Management and Mythology for a critique of QoLs, QALYs and the like.
} 
impotence (prostatectomy)? Is it unethical of a surgeon to make a recommendation based on their judgement if they have made no attempt to consider the significance for the patient, the significance within the culture, of the surgical intervention being proposed? How might one set about answering such a question? This is not a question about what is a right or wrong recommendation, not an ethical question in the standard sense of enquiring after the morally right action or the correct response to a moral dilemma, but rather a question regarding the appropriate 'resources' one believes ought to be drawn upon by the surgeon in arriving at her/his judgment. It is a question about what one should expect from those who make evaluative judgements.

One point we might bring out here is this: we could imagine a response which suggests that the surgeon should merely restrict their advice to the success-rate of the intervention, and the possible negative effects (side-effects), and others should advise on other things. Here the surgeon avoids the difficult question posed in the previous paragraph by restricting their role to simply providing the data regarding the proposed surgical intervention's success rate, side-effects and potential complications. But there are a number of reasons for finding such a response unsatisfactory: first, the term 'success' is evaluative and determines what are to count as the pertinent data hereabouts. Second, surgical interventions do not take place in a political and economic vacuum. The relative costs of different interventions will be relevant. Moreover, adjudicating between the relative costs of different interventions will involve consideration of the relative outcomes, and appraisal of outcomes goes way beyond the analysis of the data provided by RCTs. It is not merely about a surgeon acting ethically responsibly, it is about the ethical considerations that emerge from the use of finite resources. Whether one likes it or not, it is political. Another way of putting this is that good RCTs and systematic reviews of RCTs produce hard-data, ${ }^{7}$ but as soon as that data is embedded in the context of health care, and judgments are made employing that data, then there are all sorts of evaluative considerations which impact on those making judgements about medical interventions. Finally, simply in virtue of being a surgeon and being prepared to undertake the surgical intervention the surgeon in and through their actions is expressive of an evaluative stance: what is expressed to the patient is that this authority-figure believes in this intervention.

Now, if one were a surgeon and had not thought about this question before in the way we present it here in this judgement-scenario, having done so now might lead you to make a more value-literate and ethically-informed decision in future. It might lead you to make a more rationally defensible decision, which has a greater chance of being acknowledged as legitimate by one's peers. And this is surely a good thing. Imagine, then, the ability to think about such judgement-scenarios in a supported and structured forum with other people, some of whom might be 'stakeholders'. These 'stakeholders' might be people who have had (or indeed have chosen not to have) a mastectomy, had (or chosen not to have) a prostatectomy, or had an extended course of chemotherapy; they might include Macmillan nurses, nurses who have cared for people undergoing chemotherapy, and family members of those who have had a mastectomy, a prostatectomy or an extended course of chemotherapy. Maybe participation in this structured forum would further enhance the rational foundations of the surgeon's judgement and also help patients, family members of patients, and

\footnotetext{
${ }^{7}$ Whether in practice the framings of such 'evidence-based' data can itself really be regarded credibly as apolitical is a question that merits further discussion. Cf. n.3, above: arguably that framing ignores deeper questions about the structure of knowledge and the structure of society which substantively condition the meaning, results and importance of RCTs. (See also the opening of section 5, below.)
} 
nurses better understand the surgeon's views. The thought that 'stakeholders' engaging in dialogue in a supportive and structured forum will enhance value-literacy and ethical judgement in beneficial ways is the thought that Fulford's (2013) theory of Values-Based Practice (VBP) is built on.

\section{Medicine and Deliberation (Libertarianism and Values-Based Practice)}

\subsection{Liberal Deliberative Democracy}

Fulford's idea is derived from a particular brand of liberal political theory: liberal deliberative democracy. The idea is proposed in response to a perceived dilemma: while we are committed to respecting the evaluative beliefs of individuals these often conflict with the evaluative beliefs of other individuals. We want to respect each individual's values but also arrive at collective value judgements on policy issues and the like. Moreover, in arriving at collective value judgements and incorporating those into policy, we want those individuals who might still not share these values to acknowledge the legitimacy of those values-now-made-policy. How might this be achieved? Well, we can identify which are the most robust, best or correct claims. But how do we decide this in a manner which respects the evaluative claims of each individual? What we need to do, so the argument goes, is subject the claims of individuals to a non-prejudicial process whereby the claims can be exposed to the counter-claims and rational scrutiny of others in a supportive forum in the absence of the distorting influence of external forces. In such a forum, the evaluative beliefs will be subject to a process of 'natural selection' as the weaker give way to the stronger beliefs. Individuals who have submitted themselves and their evaluative beliefs to a deliberative forum will dispense with their weaker, less-defensible, beliefs and emerge with strong-because well-supported and more defensible-beliefs: either those they entered with, now revised or new ones.

Let us put this another way. Individuals hold evaluative beliefs, which often conflict with those held by other individuals. Societies, being collections of individuals, need to arrive at collective judgements on evaluative beliefs. We need to find a way of arriving at collective judgements, while respecting the beliefs of individual members (resisting authoritarianism) and establishing the legitimacy of the collective judgement, even for those for whom that collective judgement remains in conflict with their own individually-held evaluative beliefs.

If we think of liberalism as a spectrum, with libertarians at one end and liberal deliberative democrats at the other, that which determines one's position on the spectrum is the extent of the procedural demands the theorist takes to be justified in imposing on individuals. Libertarians minimise procedural demands because all demands are seen as restrictions on an individual's total freedom, even if those demands are procedural. On the other hand, liberal deliberative democrats make more demands, while still insisting on these being purely procedural (this is taken to be the 'red line', which when crossed leads one to authoritarianism). For libertarians, political institutions should be structured with one goal in mind, which in turn legitimises the authority those institutions enjoy: the maximisation of the freedom of individuals to express their preferences un-coerced. For liberal deliberative democrats, political institutions should serve the same goal, but they can do so in a more indirect manner: an institution can be said to maximise freedom in as much as it promotes reason, social stability and greater legitimacy. A rational, stable society with a legislature that is acknowledged as having legitimate authority-even by those who do not share its values-is freedom-enhancing. For liberal deliberative democrats, institutions that involve individuals in processes of deliberation promote reflection and understanding of the values of other individuals, 
and this promotes social stability and the individual's recognition of the legitimacy of the values that have become incorporated into policy. Where libertarians trust that dialogue, along with the understanding and shared values that might emerge from that, will take place spontaneously through the free association of individuals in civil society, deliberative democrats contend that such dialogue requires (or at least benefits from in important freedom-enhancing ways) promoting and facilitating by the state in structured fora, which form an integral part of the public sphere. Libertarians might charge that liberal deliberative democrats impose unjust freedom-restricting demands on individuals, in demanding that they participate in the structured deliberative fora. In contrast, liberal deliberative democrats might respond that the libertarian's reluctance to promote deliberation through structured fora does not, as the libertarian hopes and claims, result in greater individual freedom but rather subjects the dialogue undertaken in civil society to the distorting, maybe even perverting, influence of dominant socio-economic interests, such as corporate interests. Capitalist societies contain powerful interest groups, and any dialogue that feeds into policy needs to be protected from these. Structured deliberative fora established as an integral part of the public sphere create a space where, so the argument goes, dialogue can be undertaken in a manner that is conducive to free, open and un-prejudiced dialogue because it is free from the distorting influence of powerful interest groups.

\subsection{Liberal Deliberative Democracy and Health Care: Values-Based Practice}

It seems to us that the best way to understand the perceived need for VBP is via the thought that right now health care generally operates de facto on the libertarian model. This leads to a chaotic cacophony of competing value claims, which in the absence of supportive and structured fora can appear to persist in a state of chaos. In this environment, collective decisions based on evaluative judgements or beliefs transpire to perpetuate the pervading or dominant interests and biases: market interests, managerialist interests, professional interests of the individuals or group with the highest status, gender bias, ethinic/racial bias and so on; furthermore, in being encoded with these interests and biases the judgements are much less likely to be perceived as legitimate by those who do not share those evaluative beliefs. Fulford, through VBP, wants to implement the ideas of the liberal deliberative democrats and introduce supportive and structured fora where the evaluative claims of individuals (stakeholders) will, through dialogue-induced natural selection free from the distorting influence of prevailing interests and biases, be transformed into rationally-defensible beliefs with greater capacity for being perceived as legitimate.

Viewed in this light, Fulford's proposal seems interesting for two reasons:

1. because it goes beyond the "bio-ethics" and "ethics committee" approach, and engages philosophically beyond the usual areas in which medicine has tolerated, and even on occasion invited, philosophical contributions; and

2. because it serves to expose unacknowledged assumptions to scrutiny - and does so because VBP seems to re-orientate the way one might have hitherto viewed matters.

In this, latter, way it seems to fulfil the task we outlined as that of philosophy at the beginning of our paper, in contrasting this to the widespread assumption that philosophy is a proto-science. VBP reframes our way of thinking about value: it tells us that both the legitimacy of policy decisions based in collective judgements (evaluative beliefs) and the strength or fitness of those judgements 
can be enhanced, while retaining a healthy respect for the individual judgements. It finds the middle ground between the poles of on the one hand libertarian anarchy, which actually, somewhat paradoxically, leads to backdoor-authoritarianism owing to the unfettered perverting influence of powerful interest groups, and on the other hand traditional authoritarianism, derived from traditional authorities such as church and state, or in the context of health care: managers and surgeons/physicians.

\section{Medicine and Value (The Emotivist Frame is Non-Obligatory)}

So much for accentuating the positive. We believe there are, unfortunately, stronger grounds for scepticism regarding Fulford's proposal. We want to suggest that despite appearing to reframe the issues at hand, Fulford actually takes on wholesale the framework which is (was) already present. The clue has already been flagged, albeit implicitly, in what we have written in the foregoing. In VBP, Fulford proposes a quasi-deliberative solution to the current libertarian value-anarchy, while all along the problem is to be found in the conception of value which is shared by both liberal deliberative democrats and libertarians: the liberal conception of value. If we might be forgiven for stretching the frame metaphor, what we are suggesting here is that while it can seem, at first glance, like Fulford has reframed our way of approaching value in the context of health care, it transpires that he has simply remounted the same picture in the same frame. Only the mount has changed. Put less figuratively, we agree that reframing our thinking about value would be beneficial to health care, but note that Fulford has failed to achieve the required reframing because he has remained within the dominant liberal paradigm. [Ref to chapter by Brecher.] Liberal political theory itself is unphilosophical in neglecting the frame or assuming there is a possibility of a neutral frame.

There are other ways to think about value. Health care lends itself to teleological analysis, where a Conception of the Good might be useful in guiding deliberations. There might even be (we will here remain agnostic on this) good reasons for subscribing to a liberal conception of value at the nation state level, but that does not entail that those reasons carry-over into the context of health care. Fulford (2013) writes that "[t]he point of values-based practice is to support balanced decision making on individual cases where complex and conflicting values are in play within frameworks of values shared by the individuals concerned." While this has a superficial air of reasonableness about it, one might be forgiven, if one does not share Fulford's liberal assumptions, for finding it a little question-begging. It is question-begging in that internal to it is an assumption that the response to being confronted with a value-conflict should not be to simply identify the actually-stronger claim. This observation is important to note, because what we would like to bring out is the extent to which Fulford's liberalism is non-obligatory and, ironically, by his own standards authoritarian.

What we seek to draw attention to in identifying VBP as liberal is the extent to which liberalism begins by tacitly effecting a decidedly-negative valorisation of value claims, in the sense that those value claims are 'translated' into the preferences (or 'interests') of individuals. [Ref to chapters by Brecher, Hamilton]. Liberals treat value-claims as little more than expressions of individual preference(s). We suggest that this relegation of value claims to the status of preferences is unjustified; indeed, we would argue that it does violence to the true status/nature of value claims. It does not follow from the observation that individuals often express conflicting values that those values either are of equal status or ought to be considered of equal status. [Ref chapter by Kingma \& Banner] Thinking, as Fulford does, that one must treat them from the outset as of equal status, as 
equally viable expressions of preference, on pain of being authoritarian ${ }^{8}$, is to become confused. It is to fall into a kind of localised relativism. (It is an illicit deduction of a localised relativism from a-not unreasonable-observation of initial pluralism.)

The confusion emerges because in attempting to avoid authoritarianism at the level of adjudication between the conflicting claims of individuals one stipulates that each individual's claim must be considered as of equal status (until post-process). If we understand authoritarianism in the way the liberal does - as that which arises from the invocation of non-procedural authority regarding the status accorded to individual value claims - then an appeal to non-procedural authority to stipulate that all value claims must be treated, irrespective of their merits, as of equal status (prior to procedural ratification) is equally authoritarian. So pure-procedural liberals, ${ }^{9}$ and therefore Fulford too, enter into an authoritarian regress. This is the way in which modern-more or less Rawlsianliberalism is constitutively (tacitly) authoritarian. It is authoritarian in its prima facie rejection of nonneutrality between values, and in maintaining in practice, as we shall shortly see, a more or less subjectivist view of values. The conclusion of Thornton's (2011) "Radical Liberal Values-Based Practice" remains highly salient. Liberalism somehow seems to think it has a right to help itself to a 'master-value', which Fulford (2013) characterises in the rhetorically appealing language of 'mutual respect'. That really is a value, unlike the 'values' that people hold. These 'ordinary' values need respect because individuals need respecting, but they are merely preferences, even if they are held by those holding them as the most important thing in their lives, (a philosophy or an ethic or suchlike) and even if they believe (and are prepared to defend the belief with rational argument) that their values are more important than other values - some of which they may regard as simply wrong. Such a belief, it seems, stands in need of 'correction', as their values simply cannot be as important as 'mutual respect', the master-value. ${ }^{10}$

Now a liberal theorist like Fulford might reject this accusation of authoritarianism regarding the status of value claims, and argue that what he/they are seeking is neutrality between conflicting value claims. What they are doing is striving for neutrality by attaining a meta-meta-ethical position:

\footnotetext{
${ }^{8} \mathrm{Cf}$. his equation in Fulford (2013) of "authoritarianism" with a commitment to "pre-set outcomes".

${ }^{9}$ As will have become evident to a reader versed in recent political philosophy, Fulford's liberalism is of the hegemonic kind: it is broadly Rawlsian, 'pure-proceduralist'. For our objections to Rawlsian liberal political philosophy, see e.g. Read $(2011,2012)$ and Hutchinson's "Climate Change and the Liberal Programme" (forthcoming in Makoff and Read's A Political Philosophy for All Beings).

10 "What is the status of the claim that: in VBP conflicts of value are resolved primarily, not by reference to a rule prescribing a 'right' outcome, but by processes designed to support a balance of legitimately different perspectives? // Note first that although it says that conflicts of values are resolved ... this is in the context of VBP. So, it should be read as saying: conflicts of values should be resolved ... by processes designed to support a balance of legitimately different perspectives. But now we can ask, why should they? (It may be an analytic truth that they are within VBP, but we are invited to adopt this approach.) And now the worry is that this seems to be a value of a different order from the values that should be put through the process of balancing views. This seems to be a higher order value, inconsistent with VBP's own approach. This suggests a dilemma for radical VBP. It can either address the question of why we should value values in the way it suggests, at the cost of violating its own principles, or it can attempt no such question, in which case it lacks the prescriptive force that gives it teeth." (Thornton 2011, p991). We like to call this dilemma 'the Fulford fork': either liberals have to be (and ought to admit) their authoritarianism (as classical liberals often did, but Rawlsians shy away from doing), or they must give up the claim that pre-set outcomes are distinctively authoritarian. But the latter option opens up just the space we mean to occupy: the space for true rational deliberation, and thus for the development of (say) an Aristotelian alternative to liberalism.
} 
liberals are then the alleged champions of pluralism. ${ }^{11}$ However, to give all views equal status is to be committed to one (or more) of the following three claims:

1. The ontological claim that there exists nothing in the world which can settle or play a decisive role in determining which of a number of conflicting value claims is correct. Or

2. The epistemological claim that we cannot know for certain (or beyond reasonable doubt, or reliably) which of conflicting value claims, if any, are correct/true. Or

3. The substantive moral claim (or psychologically-induced stance) that we are resolutely indifferent to which views, if any, are, or can be shown to be, correct/true.

To be committed to the ontological claim entails a rejection of objectivist ethics and of any form of ethical realism (that values might be the sort of things that exist constitutively independent of our thoughts). Commitment to the epistemological claim entails non-cognitivism in practice, because we lack knowledge of the truth or otherwise of a particular moral view or claim. To be committed to option 3, the indifference option, would seem to entail that one was, at the very least tacitly, committed to a form of existential emotivism, whereby one is committed to living and acting as if emotivism (or: some form of moral subjectivism) were true. Whichever of these is the view to which Fulford is committed, what is entailed by VBP is that no moral value claim can make a specifically moral demand on any individual without their-alleged and indirect-formal consent in virtue of the claim having been legitimised by having passed through the procedures, as established by VBP.

Put another way, according to VBP, value-claims need assent from other individuals, in virtue of having passed through the deliberative process, if they are to be established as being more than mere expression of preference, opinion or interest. What we are concerned with here are the consequences of Fulford's liberal negative valorisation of the value claims for those for whom VBP is being proposed as a solution. VBP professes to avoid authoritarianism and to respect individuals' values but begins by insisting on those values being treated as nothing more than expressions of preference or interests: i.e. not distinctively evaluative beliefs at all. Consider: the only thing which can enable an individual's value judgement to achieve the status of more than mere expression of preference, or be formally recognised as politically significant, is it having been legitimised by having passed through institutionalised procedures as prescribed by the theory.

What is the alternative? Well Fulford (2013) would have us believe that the alternative to VBP's negative valorisation of value claims into interests and preferences is the authoritarian ranking of value claims by fiat. (cf. his swift move - p539 - from noting certain philosophers are "moral objectivists" to discussions of Soviet commissars imprisoning dissidents.) But this is simply not a dichotomy we need accept. Such a dichotomy is, one might say, an artefact of the very negation of substantive values that we are questioning. The dichotomy Fulford sees and tries to overcome is a result of his own failure to genuinely overcome (and then reframe) the way values have been side-

\footnotetext{
${ }^{11}$ We suspect here a confusion, among liberals such as Fulford, between process and outcome: just because we need to get (plenty of) others to agree, in a democracy, if we are to implement a policy, doesn't mean that what we put forward for agreement should be defined by that need so to agree nor reduced to it! To be fair to Fulford, we suspect that this confusion is inherited from Rawls et al-it seems fairly stark, by the time one gets to Rawls's Political liberalism, for example in Rawls's notion of the 'proviso'. (For discussion, see Read's article published at http://www.arsdisputandi.org/publish/articles/000394/article.pdf ).
} 
lined in the context of health care, especially in the context of EBM. If we reject the negative valorisation, if we resist the liberal's invitation to see all value claims as mere expressions of preference, then we find that we also come to recognise why the dichotomy with which Fulford presents us is a false one: i.e. because value claims are rationally assessable. ${ }^{12}$ While expressions of preference about such things as taste (what's your favourite flavour ice-cream?) involve no demand for rational support, value-claims do. The category of a value-claim is not reducible to an expression of preference, unless one is committed to some form of emotivism as a meta-ethical position (and/or to some substantive moral relativism). It appears to us that the most plausible reading of Fulfordian VBP is that he is so committed. Or at least: that whichever of the three options indicated above one takes, it amounts in practice to an accepting of emotivism in the political sphere, or (at least, specifically) in relation to the treatment of value-conflicts in health-related contexts. (Fulford's emotivism should not be a surprise to those familiar with his writings on VBP. He repeatedly reminds his reader of VBP's heritage in the philosophy of R.M. Hare. The observation that Hare's writings are a form of emotivism-a sophisticated form, but still a form thereof-is uncontroversial.) [add AUSTIN point]

\section{Medicine Reframed (Health and the Telos of Human Flourishing)}

We have already gestured in the direction of our proposed solution to the problem. The solution is to engage in some genuine reframing; we must reject the subterranean emotivism operative in VBP. Our proposal is what we call Flourishing-Oriented Medicine. Not EBM with a VBP add-on; no negative valorisation, simply the recognition that medical science involves (is in fact saturated by) evaluative concerns, judgments and beliefs. [Ref chapter by Tonelli] Even in the 'strictly epistemological' aspects of medical science such evaluative judgments frame and therefore permeate our investigations (contrary to the dominant self-image, represented in our opening paragraphs). These must be acknowledged and discussed in an attempt to triangulate or evaluate. This is why Fulford begins with the premise of values being in conflict. Our free-floating value-judgments can seem to be in interminable and intractable conflict because of the liberal-emotivist framework which Fulford simply accepts as unavoidable and seeks to reify institutionally through the processes of VBP. But this framework is non-obligatory. Evaluative concepts in health care have their home in a teleological framework, where to be in good health is to flourish. To be sure, there will be deep discussions and arguments and divisions about what flourishing is. But our value conflicts will seem less interminable, less intractable and less inevitable when we see that one of the reasons why our way of seeing the value of a proposed intervention might be at variance is because we had different ideas about what it was to flourish, to live a fulfilling, dignified healthy life. For we can then start to seek together genuinely to reconcile or at least 'triangulate' those ideas.

Why do we speak of 'Flourishing-Oriented' rather than 'Flourishing-Based' Medicine? Because it is about where we are (and want, all things considered, to be) headed, rather than about an alleged solid and ethically-uninflected evidence base from which we proceed on the grounds of values that are, regrettably, in practice largely taken for granted and not subject to investigation or rational critique. FOM keeps our eyes collectively on where we are going; it doesn't deduce everything from an 'evidence-base' and then worry about having to 'add back in' the values that have been left

\footnotetext{
12 Note: our understanding of rationality is intended here as a broad one. It will include much that is often illegitimately dismissed as 'emotional'. For explication, see Hutchinson (2008).
} 
missing from the picture and thus figured spontaneously. VBP is an attempt to bring the 'values' back in to the health care picture. But it mirrors the assumptions of EBM; it thinks of facts and values as radically different, and complementary. It is an attempt to 'fix' EBM. It fails, as we have shown, to take seriously that values are more than just preferences or interests.

FOM would by contrast genuinely integrate fact and value, as part of an indissoluble whole which we actually live. There is an important sense in which, insofar as values and facts actually can be extricated from each other at all, then values come first. In FOM, one would look at the state of health, of flourishing, that could ideally be achieved, and would actually be genuinely desirable (this would be a crucial part of the reconciliation project alluded to above), and at the change needed in a patient(s)/population in order to achieve it, and backcast that outcome to determine what therefore needs to be done now: what needs to be considered, what needs to be researched, what options with which to present patients, and so on. It is important to stress here that the goal, the desired outcome, of human flourishing, is an 'open-ended' goal. Keeping clearly aware of that openendedness would lessen any risk that FOM became 'authoritarian' in a genuinely troubling way, and would suggest instead that much of the requisite goal-setting and backcasting should be framed in terms of a sustainable 'via negativa': much that we take to be health services would be conceived as directed toward their own self-eliminating and the enhancement of people's (collective) autonomy. So: yes to (collective) open-endedness; but FOM would be non-liberal. It would aim with deliberate force at enhancing (certain of) people's capabilities considered over time, indeed over generations, and over a population. Moreover, the word 'deliberate' should be understood in a rich and multiple sense: a genuine (i.e. non-liberal) deliberative democracy (employing citizens' juries, etc., taking seriously deliberation as a collective rational endeavour) should be what leads this effort at deliberate discussion of and direction toward health. A preference-satisfaction model of values and of value-expression (tacitly-based, in effect, in consumer-preference, or in individualistic nondeliberation-based voting) is liberal, and is inadequate for the reasons outlined above.

FOM would entail that we look outwards to the political and ecological structure of our society, so as to see how this might (if and when it is wrongly designed or badly operating) conflict with the pursuit of flourishing. And FOM would be highly amenable to the idea of deliberative fora, but not on the liberal model. For liberalism empties out these fora of real content, by reducing values to preferences, and rejecting discussion of the frameworks (the conceptions of flourishing) within which those values gain sense. In doing so the space for rational discussion is undermined. FOM would envisage not a totting up of preferences, but a real social engagement, of human beings thinking together about how to decide the issues that structure medicine, and would factor-in prevention and precaution (including crucially across a whole population) heavily. Think what it would really be like, to have a National Health Service, rather than what we currently have: a National Illness[-treatment] Service. ${ }^{13}$

\footnotetext{
${ }^{13}$ Here, we are somewhat encouraged by the following moment, even if it is only a rather brief and isolated one, from p.128 of the King's Fund 2011 report on "Improving the Quality of Care in General Practice: From Treating IIIness to Promoting Health". Therein, "general practice is regarded as uniquely well placed not just to promote the health and well-being of the practice population." We are however discouraged by the completely trivial account of population health given on the following page: "The performance of general practices, as providers and commissioners of care, should not only be assessed in terms of whether individuals can access high-quality services. It also needs to be judged on the extent to which it meets the health needs of the wider population, including people experiencing homelessness, veterans, refugees and asylum seekers,
} 
The deepest way forward, we would suggest, is a 'via negativa', a serious emphasis on precaution and prevention, ${ }^{14}$ on the Hippocratic 'First, do no harm.' On doing less, not more. FOM would be a more (explicitly) 'political' medicine-and all the better for it. It would be a collective-a communitarian, or 'societarian' - medicine, not a liberal individualised medicine based on a scientistic fantasy that abstracts from our embodiedness and from our sociality. We are social animals. "Flourishing" includes others. I never flourish as all others decline. Flourishing is ultimately something that a population-a 'herd'-does as a whole. Think of 'herd immunity'. It is far easier to understand this as an ethical goal on the basis of FOM than it would be on the basis of VBP, where its desirability would depend on the happenstance of preference-distribution of individuals. As, in closing, we shall now seek to demonstrate...

\section{Flourishing Oriented deliberation}

By way of conclusion, let us here suggest a ('hypothetical') judgement-scenario and then ask some questions. This time, rather than of the mastectomy and prostatectomy case we discussed above, a case with yet broader social dimensions:

A deliberative forum has been established by a regional health authority to feed into policy decisions about administering vaccinations to children. The parties-stakeholders-involved in the forum include mothers, fathers, General Practitioners, Nurses, Health Visitors and Health Service managers, some of whom have medical backgrounds and some of whom have no medical background but who do have MBAs. Herd immunity is key, so as to prevent outbreaks of measles in future years or decades, ${ }^{15}$ but vaccinations are costly to buy and administer, and parents have a right to protect their children. It should go without saying that there are lots of factors to be considered. However, one matter comes to dominate proceedings and it does so because of an intersection of two popular views held by a number of those participating in the forum. The two views are:

1. That individuals should have the right to choose (for their children); and

2. That the MMR vaccine probably causes autism.

In contrast to the vantage point we (the authors of this paper and our readers) enjoy now, when there are numerous studies and a disciplinary hearing to which one can point which resoundingly undermine the truth of the autism claim, at the time our hypothetical forum occurred there were few such resources. Despite assurances from the health practitioners participating in the forum, the parents were clear they would be betraying their children, and being bad parents, if they condoned the MMR roll-out. The author of the MMR-Autism paper that provided the origins for the parents' concerns, while seen as a controversial and a maverick, had not at this stage been struck off and even the health practitioners present at the forum struggled to produce hard data to refute the autism claim. All their talk of herd immunity just felt to the parents like a request to sacrifice their

people with mental health problems, and those with drug and alcohol problems, who may not actively seek care from general practice." This name-checking exercise and the repeated use of the word "people" do not begin to substitute for a serious effort at thinking the population, 'the herd', as a whole.

${ }^{14}$ In future we hope to demonstrate how FOM, unlike EBM/VBP, can take seriously the Precautionary Principle, and on what positive effects on human flourishing (within the very real limits of knowledge, material resources, ecosystemic limits etc. to which we are subject) this is likely to have. But nothing in our critique of VBP depends upon that future critique.

${ }^{15}$ As happened in 2013 in South Wales. 
children, or as a smokescreen for cost-reduction strategies (everyone knew that MMR was cheaper than individual Rubella, Measles and Mumps vaccinations). In the absence of a refutation of the Autism claim then the individuals should clearly have the right to be cautious and protect their children. This thought was buttressed (principle 1) by a widespread valorisation of a liberal individual 'right to choose'.

The point is that for VBP all participants have interests or preferences that are being expressed here, and it is only the outcome of the forum that can transform some of those into legitimate value claims that can be incorporated into policy. But the truth is that in our scenario the parents were expressing 'self-interest' based in a combination of unreflective individualism and poor knowledge. (And that liberal principles made it particularly difficult to resist this combination.) Those advocating the vaccination programme were advocating a robust well-thought-through and supported evaluative judgement regarding public health. But: they lost.

While VBP would in this case presumably have supported the potentially-disastrous (and actuallyharmful) witchhunt against the MMR vaccine, and thus ('ironically') would have undermined the result that one might have expected a 'science-based'-approach to have given, FOM would not. For, in Flourishing-Oriented Medicine, people are more likely to think carefully of what the precautionary approach would be than to demand 'evidence' (that reducing the MMR vaccine will actually lead to serious harms due to its reduction of herd-immunity). Crucially, in FOM, the 'herd' and not just the individual 'stakeholders' will have a role. This is how FOM, in emphasising the flourishing of the community as a whole, is superior to the liberal (individualistic) approach of VBP.

How would this work, in FOM? Over time, one would have reason to hope that understanding of the kinds of points we make in sketching out FOM, in section 5 above, would become more general, among medical spheres and also among society more generally. A society that comes to understand itself as directed toward its own flourishing will naturally choose according to the kind of precepts indicated in FOM. But what about in the meantime? In the kind of deliberative forum we envisagein a deliberative forum structured according to the precepts of FOM rather than of VBP-how would the deliberation and decision-making be approached, and why are we confident that it would be likely to have a different outcome than what actually occurred historically, which would we think merely have been undergirded by a Fulfordian approach?

There are various possibilities here. Briefly, beyond what we have already said, let us make the following two-(we think) decisive-points:

- While VBP is 'purely procedural', FOM has objectives built into it. Participants would be enjoined to consider these. Herd-immunity wouldn't be something that individuals might or might not decide that they valued; it would be structured into the framework of the discussion from the outset. (Fulford might consider this 'authoritarian'; we humbly submit that it is, in fact, merely sane.)

- If one were unconfident of this being enough, one could also introduce additional 'stakeholders' into the deliberative process. One could explicitly create representatives for the community as a whole; and/or for unborn future generations; etc. One could strongly empower such representatives in the deliberative forum: for example, wouldn't it be reasonable to suggest that any proposed outcome that were unacceptable to the voice in the forum representing all those not present, and representing in particular the powerless 
future people, should be unacceptable in toto ${ }^{16}$ Fulford might think such arrangements for 'proxy representatives' illiberal and undemocratic. We would respond that, while they might be 'illiberal', this would/should not necessarily be judged a criticism (for the reasons we have offered above, concerning why a liberal political philosophy can fail to help a society to flourish, etc.); and that our proposals would arguably be more democratic than Fulford's. For surely a people is not merely a time-slice; a people-a demos-exists over time, and thus should include the future ones. ${ }^{17}$

Our MMR 'case-study' here undergirds what we have argued. That, rather than 'complement' EBM with VBP, EBM should be sublated. VBP should be dropped, and EBM could morph then into FOM. No longer positivistic and scientistic, and more honestly ethical and political. With deliberative fora that, far from being mere tick-box exercises or amalgamations of individuals' preferences, are actually likely to produce the best and most robust decisions. Decisions that are likely to be compatible with both medical science and human flourishing.

This is how philosophy might be able to actually help enrich medicine and health care. And thus even, dare we say it, to help us all.

\section{Bibliography}

Atkins, Peter (2011) On Being: A scientist's Exploration of the Great Questions of Existence. Oxford: Oxford University Press.

Bausell, R. Barker (2007) Snake Oil Science. New York: Oxford University Press USA.

Carel, Havi (2008) IIIness. Oxford: Acumen

Fulford, K.W.M. (1989) Moral Theory and Medical Practice. Cambridge: Cambridge University Press

Fulford, K.W.M. (2013). "Values-Based Practice: Fulford's Dangerous Idea." Journal of Evaluation in Clinical Practice, 19. 537-546

Hawking, Stephen (2010) The Grand Design. Oxford: Oxford University Press.

Hutchinson, Phil (2008) Shame and Philosophy: An Investigation in the Philosophy of Emotions and Ethics. Basingstoke: Palgrave

\footnotetext{
${ }^{16}$ Our suggestions here are in part modelled on Read's suggestions in his proposals for deliberative 'guardians for future generations':

http://www.greenhousethinktank.org/files/greenhouse/home/Guardians inside final.pdf . Read suggests (t)here, in a way useful to the present chapter, that such guardians could voice the future ones - as we are suggesting that the community needs genuinely to be voiced.

We will expand on this parallel, in future work.

${ }^{17}$ See again Read's report on guardians, especially the opening two sections. (In the particular respect under consideration here, we are closer to Burke than to Rousseau. A people is a necessarily-asymmetrical 'partnership' between the future, the past, and the present. It is not a 'contract' in the liberal - presentist sense of that word. Being a person who is actually part of a society, and part of a society that is sane, requires that we care for the future. Real health care is a key part of this.)
} 
----(2011) "The Philosopher's Task: Values-Based Practice and Bringing to Consciousness Underlying Philosophical Commitments." Journal of Evaluation in Clinical Practice.

----(2013) “What Have the Philosophers Ever Done For Us?” blog post of a talk given in 2011. http://viewfromthehutch.blogspot.co.uk/2013/06/what-have-philosophers-ever-done-for-us.html Loughlin, Michael (2002) Ethics, Management and Mythology. Radcliffe.

Read, Rupert (2011) "Beyond an Ungreen-Economics-Based Political Philosophy" International Journal of Green Economics.

----(2012) “On Philosophy's (lack of) Progress” In Wittgenstein and Plato, eds. Luigi Perissinotto and Begona Ramon Camara. Basingstoke: Palgrave MacMillan

Taleb, Nassim Nicholas (2007) The Black Swan. London: Penguin

Thornton, Tim (2011) "Radical Liberal Values-Based Practice" Journal of Evaluation of Clinical Practice.

Report:

King's Fund (2011) "Improving the quality of care in general practice: From treating illness to promoting health"

Add refs to chapter by Kingma \& Banner, Brecher, Hamilton, Tonelli 